\title{
BMJ
}

\section{Effect of peer support on prevention of postnatal depression among high risk women: multisite randomised controlled trial}

\author{
C-L Dennis, associate professor and Canada research chair in perinatal community health, ${ }^{1,2} \mathrm{E}$ Hodnett, \\ professor and Heather M Reisman chair in perinatal nursing research, ${ }^{1} \mathrm{~L}$ Kenton, trial coordinator, ${ }^{1} \mathrm{~J}$ Weston, \\ senior trial coordinator, ${ }^{1}$ I Zupancic, assistant professor of paediatrics, ${ }^{3}$ D E Stewart, university professor \\ and Lillian Love chair in women's health, ${ }^{2} \mathrm{~A}$ Kiss, biostatistician ${ }^{4}$
}

$\overline{1}$ Lawrence S Bloomberg Faculty of Nursing, University of Toronto, Toronto, Canada

${ }^{2}$ Department of Psychiatry, Faculty of Medicine, University of Toronto, Toronto, Canada

${ }^{3}$ Beth Israel Deaconess Medical Center, Boston, Massachusetts, USA

${ }^{4}$ Department of Research Design and Biostatistics, Sunnybrook Health Sciences Centre, Toronto, Canada

Correspondence to: C-L Dennis cindylee.dennis@utoronto.ca

Cite this as: $B M J$ 2009;338:a3064 doi:10.1136/bmj.a3064

\section{ABSTRACT}

Objective To evaluate the effectiveness of telephone based peer support in the prevention of postnatal depression.

Design Multisite randomised controlled trial.

Setting Seven health regions across Ontario, Canada.

Participants 701 women in the first two weeks postpartum identified as high risk for postnatal depression with the Edinburgh postnatal depression scale and randomised with an internet based randomisation service.

Intervention Proactive individualised telephone based peer (mother to mother) support, initiated within 48-72 hours of randomisation, provided by a volunteer recruited from the community who had previously experienced and recovered from self reported postnatal depression and attended a four hour training session.

Main outcome measures Edinburgh postnatal depression scale, structured clinical interview-depression, state-trait anxiety inventory, UCLA loneliness scale, and use of health services.

Results After web based screening of 21470 women, 701 (72\%) eligible mothers were recruited. A blinded research nurse followed up more than $85 \%$ by telephone, including 613 at 12 weeks and 600 at 24 weeks postpartum. At 12 weeks, $14 \%$ (40/297) of women in the intervention group and $25 \%(78 / 315)$ in the control group had an Edinburgh postnatal depression scale score $>12\left(X^{2}=12.5\right.$, P 0.001 ; number need to treat $8.8,95 \%$ confidence interval 5.9 to 19.6 ; relative risk reduction $0.46,95 \%$ confidence interval 0.24 to 0.62 ). There was a positive trend in favour of the intervention group for maternal anxiety but not loneliness or use of health services. For ethical reasons, participants identified with clinical depression at 12 weeks were referred for treatment, resulting in no differences between groups at 24 weeks. Of the 221 women in the intervention group who received and evaluated their experience of peer support, over $80 \%$ were satisfied and would recommend this support to a friend.
Conclusion Telephone based peer support can be effective in preventing postnatal depression among women at high risk.

Trial registration ISRCTN68337727.

\section{INTRODUCTION}

Postnatal depression is one of the most common forms of maternal morbidity after delivery with a prevalence rate of about $13 \% .{ }^{1}$ Studies have clearly documented the negative health consequences of postnatal depression for women and their families. Infants and children are particularly vulnerable because of impaired maternal-infant interactions ${ }^{2}$ and negative perceptions of infant behaviour, ${ }^{3}$ which have been linked to attachment insecurity, ${ }^{45}$ delay in emotional developmental, ${ }^{46}$ and social and interaction difficulties. $^{78}$ Child neglect or abuse ${ }^{9}$ and maternal and infant mortality are also rare but real consequences.

Although extensive research suggests the cause of postnatal depression is multifactorial, epidemiological studies and meta-analyses of predictive studies have consistently highlighted the importance of psychosocial variables. ${ }^{1011} \mathrm{~A}$ recent Cochrane review showed that postnatal depression can be treated with psychosocial and psychological techniques. ${ }^{12}$ The results from another Cochrane review, however, pointed to the need for rigorous evaluations of preventive inter ventions. $^{13}$

Detailed analyses of social support variables in predictive studies clearly show a significant increase in the risk of postnatal depression in women who do not have someone to talk openly with who has shared and understood a similar problem, ${ }^{14}$ lack an intimate confidant or friend, ${ }^{14-17}$ do not receive support without having to ask for it, ${ }^{14}$ and feel socially isolated. ${ }^{18}$ Depressed mothers participating in a population based study commonly said that they were depressed because of "lack of support" and "feeling isolated." 19 When asked what advice they would give to new mothers with postnatal depression, the most common 
suggestion was "find someone to talk to." Another population based study found that depression scale ${ }^{20}$ scores were significantly correlated with maternal perceptions of support from other women with children. $^{21}$ Thus, the provision of support from an experienced mother might be a simple intervention with the potential to prevent postnatal depression.

We evaluated the effect of telephone based peer (mother to mother) support on preventing postnatal depression among women identified as high risk within the first two weeks postpartum. Our hypothesis was that fewer women who received peer support would show evidence of postnatal depression at 12 weeks postpartum than those who did not receive peer support. We defined postnatal depression as a score $>12$ on the Edinburgh postnatal depression $\operatorname{scale}^{20}$ at 12 weeks postpartum, a measure and cut-off score used internationally by clinicians and researchers. ${ }^{22} 23$

\section{METHODS}

\section{Participants}

Women were recruited from seven large health regions and their corresponding public health departments across Ontario, Canada, between November 2004 and September 2006. In Ontario, as part of standard postpartum care each mother receives a telephone call from a public health nurse often in the 24-48 hours after hospital discharge. At this time, a public health nurse with a web based system briefly introduced and screened potential participants. This system did not provide the nurse with a depression scale score but only informed her if the mother was potentially eligible for participation. If a mother scored $>9$ on the Edinburgh postnatal depression scale and provided verbal consent, contact information was entered into the system. We selected a score $>9$ on the basis of research suggesting that low mood in the early postpartum period predicts postnatal depression. ${ }^{1124}$ The trial coordinator downloaded the contact information daily and telephoned potential participants to provide a detailed explanation and assess eligibility. Eligible participants were all new mothers about two weeks postpartum or less who were at least 18 years of age, able to speak English, had a live birth, and were discharged home from hospital. We excluded women whose babies were not discharged home with the mother and women who were currently taking antidepressant or antipsychotic drugs.

\section{Design and procedures}

We carried out a multisite randomised controlled trial (figure). After informed consent procedures, the trial coordinator obtained baseline data and randomised eligible participants. Randomisation was centrally controlled with a web based randomisation service (www.randomize.net), with stratification based on self reported history of depression, a known risk factor for postnatal depression. ${ }^{111}$ Women allocated to the control group had access to standard community postpartum care, which could have included, if available, the mother proactively seeking the services from public health nurses, physicians, other providers, and various community resources, including drop-in centres. Women allocated to the intervention group had access to all standard postpartum care in addition to being matched with a peer volunteer. Research nurses blinded to group allocation telephoned all participants at 12 and 24 weeks postpartum to assess trial outcomes. At 12 weeks, women in the intervention group answered questions regarding their experience with the peer volunteer via a mailed questionnaire. ${ }^{25}$ While trial participants and peer volunteers could not be blinded to group allocation, health professionals and service providers of standard community postpartum care were not informed of any mother's participation in the trial or group allocation.

\section{Intervention}

Among women allocated to the intervention group, the volunteer coordinator matched participants and peer volunteers based on residency and ethnicity if the mother desired. Telephone contact was to be initiated in the 48-72 hours after trial randomisation. Based on previous research related to maternal dissatisfaction with peer support, ${ }^{2526}$ the peer volunteers were requested to make a minimum of four contacts and then to interact as deemed necessary. To document initiation of the intervention, the volunteer coordinator interacted with the peer volunteer one week after

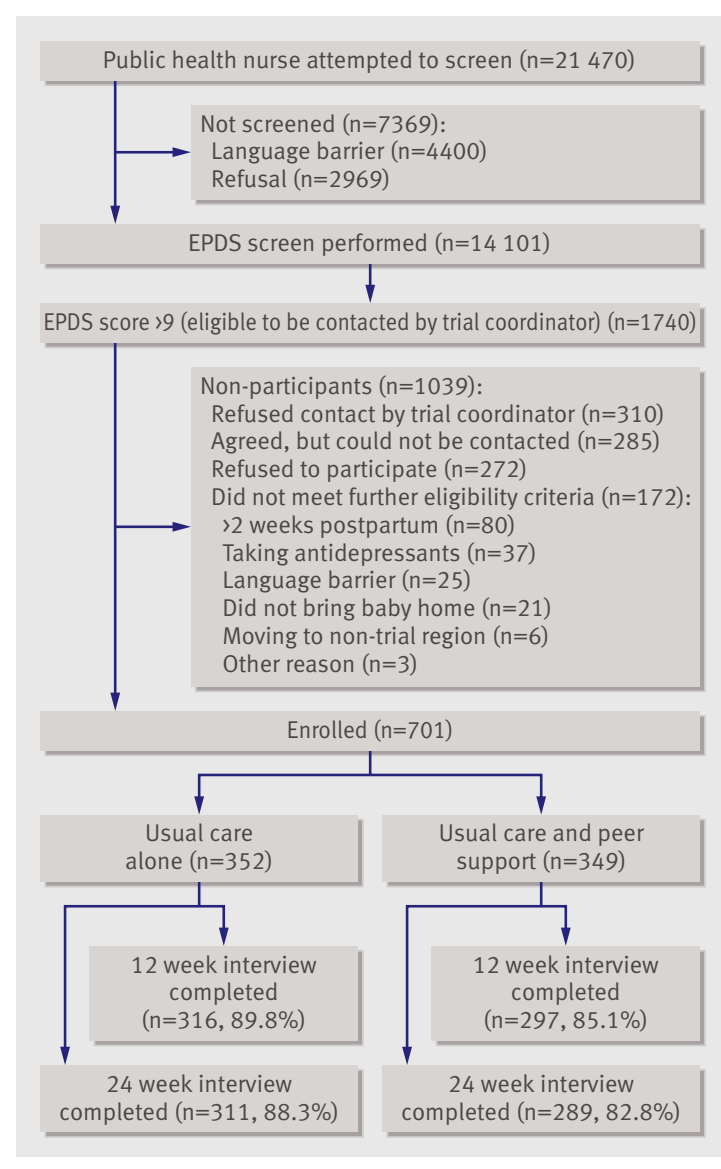

Flow of participants through trial 
matching to confirm that contact was made with the participant. All peer volunteers were requested to complete an activity $\log ^{2526}$ for each woman supported to document specific intervention activities and duration to 12 weeks postpartum.

Peer volunteer recruitment and training-Through the distribution of flyers, ads in the local newspapers, and word of mouth, 204 women from the community volunteered and met the selection criteria: ability to speak and understand English and self reported history of and recovery from postnatal depression. Peer volunteers were recruited from all health regions and the number recruited was based on region size and ranged from 12 to 66 . We employed a paid peer volunteer coordinator to organise recruitment of peer volunteers and obtain informed consent; conduct training sessions for peer volunteers; match women with an appropriate peer volunteer; and monitor implementation of the intervention. All peer volunteers participated in a four hour training session. The focus of the training was to develop skills required to provide effective telephone based support and to make referrals to health professionals as necessary; role playing was an important training strategy. A takehome 121 page training manual developed and piloted by the principal investigator ${ }^{25}$ was distributed to all new peer volunteers to guide the training session and intervention. During the training sessions, the peer volunteers were given activity logs to complete for each supported mother. Most peer volunteers who participated in the trial were married $(n=168,82 \%)$ and had some further education beyond high school $(\mathrm{n}=187$, $91 \%) ; 61 \%(\mathrm{n}=125)$ had had more than one pregnancy and $41 \%(n=85)$ were employed, either full time or part time, outside the home. Over half $(\mathrm{n}=93,54 \%)$ self reported their ethnicity as non-Canadian. Each peer volunteer who actively participated in the trial and was matched with a participant $(\mathrm{n}=175)$ on average supported two women (mean 1.97, SD 1.50), with a range from one to seven.

\section{Outcome measures}

Postnatal depression was assessed using the Edinburgh postnatal depression scale ${ }^{20}$ and the structured clinical interview for depression (SCID). ${ }^{27}$ The depression scale is not diagnostic but is by far the most commonly used measure in research to assess symptoms of postnatal depression, including in treatment and prevention trials. $^{22232829}$ The recommended cut-off score of $>12$ on the depression scale indicates probable depression $^{20}$ and has been validated by standardised psychiatric interviews with large samples. This measure has well documented reliability and validity in many languages. ${ }^{30}$ The clinical interview is a diagnostic measure for depression and has excellent evidence of reliability and validity when administered face to face. ${ }^{31}$ Our secondary outcomes included the statetrait anxiety inventory, ${ }^{32}$ the short version UCLA loneliness scale ${ }^{33}$ and the health service utilisation and cost of care questionnaire,${ }^{34}$ which examined the use of 15 diverse health professionals and services (such as walk-in clinic, emergency department). Outcome assessors were trained in data collection procedures and all self reported measures were piloted and have good psychometric properties. ${ }^{253536}$

\section{Sample size}

At the time we developed the trial, only one quasiexperimental postnatal depression prevention study previously identified women at risk by assessing depressive symptoms at baseline. ${ }^{37}$ Trials of treatment for postnatal depression that have included these assessments, however, have reported spontaneous recovery rates $($ score $<13$ ) in control groups of 25 $40 \% .{ }^{38-40}$ Furthermore, the difference in recovery rates between groups in these trials was $27-55 \%$, with $66-80 \%$ of women in the intervention group being classified as not depressed at follow-up for the primary outcome. To calculate the sample size, we conservatively assumed that $30 \%$ of women in the control group who scored $>9$ at screening would have postnatal depression (score $>12$ ) at 12 weeks postpartum. We based our sample size on our ability to detect a moderate decrease of 10 percentage points to a rate of $20 \%$ among women in the intervention group. Thus, with $80 \%$ power, a two tailed $\alpha$ error of 0.05 , and using a test of two independent proportions to find a $10 \%$ reduction in the rate of postnatal depression by 12 weeks postpartum, we required a sample size of 586 (293 per group). We therefore planned to enrol 700 to allow for losses to follow-up.

\section{Statistical analysis}

All data were collected by phone interview and were entered directly on a Microsoft Access database. Built in logic and range checks allowed for immediate correction of errors and insertion of missing data. Data were analysed with SAS version 9.1 and an intention to treat approach. The biostatistician completed an interim analysis of the primary outcome and provided results to the data safety monitoring committee, who had no safety concerns. We used a significance level of 0.05 for the primary outcome of postnatal depression and 0.01 for secondary outcomes to account for multiple comparisons. Continuous variables were analysed with two sample two sided $t$ tests. For binary variables, we carried out $\chi^{2}$ analyses and have presented odds ratios with $95 \%$ confidence intervals. To assess the change over time across groups (that is, a group by time interaction) for the primary outcome, we ran generalised estimating equation models, with one model looking at the change from baseline to 12 weeks and the second looking at the change from baseline to 24 weeks.

We used multiple logistic regression analysis to assess the effect of the intervention on postnatal depression at 12 weeks after controlling for baseline characteristics. Before analysis, we assessed the baseline variables for the presence of multicollinearity. We retained only one member of a correlated set (significant correlation coefficient $>0.8$ ) for the final model. To identify which variables offered a significant 
contribution to the prediction of depression scores, in addition to group status, the regression modelling technique $^{41}$ involved looking initially at a model with only the key predictor variable of interest (group status) and the dependent variable (score $>12$ at 12 weeks postpartum). The parameter estimate signifying the relation between group status and the dependent variable was noted and then one of the covariates was added to this model. We noted whether this new covariate changed the parameter estimate for the key variable group status by more than $10 \%$. If it did, we retained this variable for the final multivariable model. This procedure was repeated for each individual covariate, resulting in a reduced set of variables for the final logistic regression model.

\section{RESULTS}

Flow of participants, follow-up, and sample characteristics Of the 21470 attempted screens with the depression scale by public health nurses within the first two weeks postpartum, $4400(20.5 \%)$ could not be completed because of language barriers (figure). Out of the remaining 17070 attempts, $14101(82.6 \%)$ women agreed to be screened. Of these, $1740(12.3 \%)$ scored $>9$ and $1430(82.2 \%)$ agreed to be contacted by the trial coordinator to provide a detailed explanation and to assess for further eligibility. There was no difference in mean score between those who did and did not agree to be contacted (12.55 (SD 2.84) v 12.43 (SD 3.34), $t=0.63$, $\mathrm{P}=0.53)$. Two hundred and eighty five $(19.9 \%)$ women could not be reached by the trial coordinator after a minimum of three telephone attempts. Again, there was no difference in mean scores between those who were and were not contacted $(12.28(\mathrm{SD}=2.63) v 12.34$ (SD 2.85), $t=0.26, \mathrm{P}=0.80)$. One hundred and seventy two $(15 \%)$ women were ineligible; the most common reasons being $>2.5$ weeks postpartum $(n=80)$ and current use of antidepressants $(n=37)$. Of the 973 eligible women, $272(28 \%)$ declined enrolment, most commonly citing a lack of interest $(\mathrm{n}=186)$. In total, 701 women agreed to participate, resulting in a $72 \%$ acceptance rate.

Table 1 shows characteristics of the participants. There were no clinically important differences between the two groups. The mean scores at baseline were 12.50 (SD 2.80) in the intervention group and 12.62 (SD 2.76) in the control group. At 12 weeks postpartum, $613(87.4 \%)$ participants completed the follow-up telephone interview, decreasing slightly to $600(85.6 \%)$ participants at 24 weeks. There were no baseline differences between women included in the analyses and those who were lost to follow-up at 12 weeks. To assess for blinding of the outcome assessor, at the end of the interview the data collection nurses indicated whether they thought the participant was in the control group or the intervention group or they did not know. At the 12 week interview, the data collection nurses had no opinion regarding which group 595 (97\%) women were allocated to; a similar rate was found at the 24 week interview ( $\mathrm{n}=588,98 \%$ ).

\section{Clinical outcomes}

The generalised estimating equation model indicated a significant difference in the proportion of postnatal depression between groups from baseline to 12 weeks.

Table 1|Baseline characteristics of randomised participants. Figures are numbers (percentages) of women

\begin{tabular}{lcc} 
& $\begin{array}{c}\text { Peer support group } \\
(\mathbf{n}=349)\end{array}$ & $\begin{array}{c}\text { Control group } \\
(\mathbf{n}=352)\end{array}$ \\
Baseline EPDS score >12 & $131(38)$ & $144(41)$ \\
\hline Age (years): & $15(4)$ & $11(3)$ \\
\hline$<20$ & $271(78)$ & $275(78)$ \\
\hline $20-34$ & $63(18)$ & $66(19)$ \\
\hline$\geq 35$ & $323(93)$ & $323(92)$ \\
\hline Married/cohabiting & $12(3)$ & $10(3)$ \\
\hline Completed education: & $58(17)$ & $87(25)$ \\
\hline Elementary & $93(27)$ & $124(35)$ \\
\hline High school & $138(40)$ & $54(15)$ \\
\hline College & & $215(61)$ \\
\hline $\begin{array}{l}\text { Undergraduate } \\
\text { university }\end{array}$ & $48(14)$ & $137(39)$ \\
\hline Graduate university & $198(57)$ & $59(17)$ \\
\hline Self reported ethnicity: & $275(79)$ & \\
\hline Canadian & $72(21)$ & \\
\hline Other & & \\
\hline Born in Canada: & $153)$ & \\
\hline Yes & & \\
\hline No & & \\
\hline
\end{tabular}

No of years in Canada for immigrant women:

\begin{tabular}{lcl}
\hline$\leq 5$ & $57 \dagger(38)$ & $65(48)$ \\
\hline$>5$ & $94(62)$ & $72(53)$ \\
\hline
\end{tabular}

Annual household income (\$C):

\begin{tabular}{lcc}
\hline $0-19999$ & $22 \ddagger(9)$ & $27(11)$ \\
\hline $20000-39999$ & $33(13)$ & $44(18)$ \\
\hline $40000-59999$ & $36(15)$ & $39(16)$ \\
\hline $60000-79999$ & $44(18)$ & $42(17)$ \\
\hline$\geq 80000$ & $111(45)$ & $94(38)$ \\
\hline $\begin{array}{l}\text { History of any } \\
\text { depression }\end{array}$ & $241(69)$ & $242(69)$ \\
\hline $\begin{array}{l}\text { History of postnatal } \\
\text { depression }\end{array}$ & $22(6)$ & $35(10)$ \\
\hline $\begin{array}{l}\text { Primiparous } \\
\text { Vaginal delivery }\end{array}$ & $207(59)$ & $209(59)$ \\
\hline Breast feeding & $227(65)$ & $231(66)$ \\
\hline
\end{tabular}

Satisfaction with support from baby's father:

\begin{tabular}{lcc}
$\begin{array}{l}\text { Very satisfied/ } \\
\text { satisfied }\end{array}$ & $269(78)$ & $269(77)$ \\
\hline OK & $46(13)$ & $47(13)$ \\
\hline $\begin{array}{l}\text { Unsatisfied/very } \\
\text { unsatisfied }\end{array}$ & $26(8)$ & $25(7)$ \\
\hline Not in contact & $6(2)$ & $10(3)$ \\
\hline $\begin{array}{l}\text { No family member or } \\
\text { friend to help }\end{array}$ & $42(12)$ & $41(12)$ \\
\hline $\begin{array}{l}\text { No one with baby or } \\
\text { young children to talk to }\end{array}$ & $66(19)$ & $61(17)$ \\
\hline 2 years in current home & $165(47)$ & $163(46)$
\end{tabular}

$<2$ years in current home

ression scale.

*Most common were South Asian (such as Indian, Pakistani), East/ Southeast Asian (such as Chinese), Caribbean, and African. Other ethnic origins included Arab, South American, and Eastern/Southern European. $\dagger n=151$ for intervention group, 137 for control group.

$\ddagger n=246$ for intervention group, 246 for control group. 
Women in the intervention group were significantly less likely to have symptoms of postnatal depression at the 12 week assessment than those in the control group (odds ratio 2.1, 95\% confidence interval 1.38 to 3.20 ). Specifically, $14 \%(40 / 297)$ of women in the intervention group had a score $>12$ compared with $25 \%$ $(78 / 315)$ in the control group $\left(\chi^{2}=12.5, \mathrm{P}<0.001\right.$; number needed to treat $8.8,5.9$ to 19.6 ; relative risk reduction $0.46,0.24$ to 0.62 ). These results suggest women who received the peer support intervention were at half the risk of developing postnatal depression at 12 weeks postpartum than those in the control group. We found no significant group differences at 24 weeks $\left(\chi^{2}=2.53, \mathrm{P}=0.11\right)$, when $11 \%(33 / 289)$ of women in the intervention group and 14\% (43/311) in the control group had a score $>12$ (odds ratio $1.22,0.75$ to 1.98 ). This 24 week finding was expected considering that this was a prevention trial and for ethical reasons any participants identified at 12 weeks with severe depression or who had a score $>20$ were referred to their local public health department for treatment. Confirmation of referral for treatment was noted when women in the control group reported more home visits by a public health nurse at the 24 week assessment than those in the intervention group (4.45 (SD 3.49) v 3.02 (SD 2.54); $t=2.21, \mathrm{P}=0.03)$.

The accuracy of our diagnostic data can be questioned. We might have underestimated the training needs of the data collection nurses in relation to completing the structured clinical interview over the telephone with our multiethnic sample. We also had to use a shortened version of the depression module because of the feasibility of administering a clinical interview via telephone with mothers of young infants. Only $37(6 \%)$ women in the whole sample were identified with clinical depression at 12 weeks postpartum (14/297 (5\%) in intervention group and 23/315 $(7 \%)$ in control group). This prevalence is significantly lower than the overall 13\% reported by O'Hara and Swain $^{1}$ in a meta-analysis of 59 studies and the $12 \%$ rate found with interview based methods (31 studies), which included a $11 \%$ estimate based on research diagnostic criteria (19 studies). It is also inconsistent with research clearly suggesting women with depressive symptoms in the early postpartum period are at significantly higher risk of developing postnatal depression..$^{20242-48}$ The uncertain accuracy of our data should highlight the problems associated with using generalist nurses as data collectors administering the interview over the telephone with a multicultural sample and the need to use complete interview modules, despite feasibility issues.

At 12 weeks postpartum, $61(21 \%)$ women in the intervention group had a score $>44$ on the state-trait anxiety inventory compared with $86(27 \%)$ in the control group (odds ratio $1.44,0.99$ to $2.10 ; \chi^{2}=3.66$, $\mathrm{P}=0.055$ ); we found no significant group differences at 24 weeks postpartum. Table 2 shows mean scores related to all trial outcomes including loneliness and total use of health services. At 12 weeks comparable numbers of women in the intervention $(n=11,4 \%)$ and control $(\mathrm{n}=19,6 \%)$ groups were taking antidepressants $\left(\chi^{2}=1.70, \mathrm{P}=0.19\right)$. At 24 weeks there was no significant difference in antidepressant use between the groups (16 $(6 \%)$ v $\left.29(10 \%), \chi^{2}=3.05, \mathrm{P}=0.08\right)$.

We used multiple regression analysis to assess the effect of the peer support intervention on postnatal depression after controlling for baseline characteristics that were significantly related to the screening depression score in univariate analysis-including nonCanadian ethnicity $\left(\chi^{2}=16.16, \mathrm{P}<0.001\right)$, not born in Canada $\left(\chi^{2}=13.93, \mathrm{P}=0.002\right)$, and less than five years in Canada $\left(\chi^{2}=5.19, \mathrm{P}=0.02\right)$. Multicollinearity was not a concern among the independent variables in the model before analysis. The modelling procedure resulted in a final model, which included the variables trial group status $(\mathrm{P}<0.001)$, history of depression $(\mathrm{P}<0.001)$, and no other individual to talk to who has a baby or young children $(\mathrm{P}<0.001)$ (table 3$)$. The Hosmer-Lemeshow goodness of fit test resulted in a $\mathrm{P}$ value of 0.95 , indicating a good model fit for the logistic regression model.

\section{Application of intervention}

Out of the 349 women randomised to the intervention group, there was clear documentation of some form of initiation of the intervention in 328 (94\%). Among

$\overline{\text { Table 2|Mean (SD) scores for postnatal depression, anxiety, }}$ loneliness, and use of health services at 12 and 24 weeks according to group

\begin{tabular}{|c|c|c|c|c|}
\hline $\begin{array}{l}\text { Time } \\
\text { (weeks) }\end{array}$ & Peer support & Control & $\mathrm{t}$ & $P$ value \\
\hline \multicolumn{5}{|l|}{ EPDS: } \\
\hline $12^{*}$ & $7.93(4.68)$ & $8.89(5.24)$ & 2.37 & 0.02 \\
\hline $24 \dagger$ & $7.00(4.66)$ & $7.61(4.59)$ & 1.62 & 0.10 \\
\hline \multicolumn{5}{|c|}{ State-trait anxiety inventory: } \\
\hline 12 & $35.10(11.85)$ & $36.88(12.84)$ & 1.77 & 0.08 \\
\hline 24 & $33.63(11.01)$ & $34.40(12.07)$ & 0.82 & 0.41 \\
\hline \multicolumn{5}{|c|}{ UCLA loneliness scale: } \\
\hline 12 & $19.59(6.16)$ & $20.14(6.31)$ & 1.08 & 0.28 \\
\hline 24 & $18.76(6.34)$ & $19.44(6.00)$ & 1.35 & 0.17 \\
\hline \multicolumn{5}{|c|}{ Health service use: } \\
\hline 12 & $4.97(1.62)$ & $4.85(1.52)$ & 0.90 & 0.37 \\
\hline 24 & $2.83(1.53)$ & $2.86(1.62)$ & 0.21 & 0.83 \\
\hline
\end{tabular}

EPDS=Edinburgh postnatal depression scale.

${ }^{*} n=297$ for peer support group, 315 for control group. $\dagger n=289$ for peer support group, 311 for control group.

Table 3 |Variables retained in multiple logistic regression model predictive of EPDS $>12$ at 12 weeks

\begin{tabular}{|c|c|c|c|c|}
\hline Variable & Estimate & $X^{2}$ & $P$ value & $\begin{array}{c}\text { Odds ratio } \\
(95 \% \mathrm{Cl})\end{array}$ \\
\hline Study group & -0.41 & 13.69 & 0.0002 & $\begin{array}{c}0.44(0.28 \text { to } \\
0.68)\end{array}$ \\
\hline $\begin{array}{l}\text { History of any } \\
\text { depression }\end{array}$ & -0.55 & 26.24 & $<0.0001$ & $\begin{array}{c}0.33(0.21 \text { to } \\
0.50)\end{array}$ \\
\hline $\begin{array}{l}\text { Someone with } \\
\text { baby or young } \\
\text { children to talk } \\
\text { to }\end{array}$ & 0.42 & 11.69 & 0.0006 & $\begin{array}{c}2.34 \text { (1.44 to } \\
3.80)\end{array}$ \\
\hline
\end{tabular}
EPDS=Edinburgh postnatal depression scale. 
these women, $219(67 \%)$ had activity logs completed by their peer volunteer. Mothers received a mean of 8.8 (SD 6.0) contacts with their peer volunteers. In total, 1921 contacts were documented. Half $(n=951)$ were telephone conversations initiated by the peer volunteer, with a mean duration of 14.1 minutes (SD 18.5, range 1-180). Six hundred and forty one (33\%) messages were left on mothers' answer machines; in 151 instances $(8 \%)$ peer volunteers also telephoned mothers but were unable to leave a message. Only 124 $(7 \%)$ contacts were initiated by the mothers, $8(0.4 \%)$ were face to face visits, and $45(2 \%)$ were email interactions. Of all the mothers in the intervention group with documented peer interaction $(n=328)$, almost a third $(n=95,29 \%)$ of the peer volunteermother matches actively continued past the 12 weeks during which the intervention was monitored.

While there was no relation between screening depression scores and peer volunteer interactions, scores at 12 weeks postpartum were correlated to total number of peer volunteer contacts $(r=0.25, \mathrm{P}<0.001)$ and number of conversations $(r=0.25, \mathrm{P}<0.001)$. In particular, women who had a score $>12$ at 12 weeks had significantly more contacts with their peer volunteer than those with a score $\leq 12$ (11.96 (SD 6.96) v8.30 (SD 5.86); $t=2.97, \mathrm{P}=0.003)$; we found similar results with total number of conversations $(t=3.61, \mathrm{P}<0.001)$.

\section{Maternal satisfaction with intervention}

Two hundred and twenty one (63\%) women in the intervention group returned mailed evaluations of their experiences with peer volunteers. Overall, $81 \%$ $(n=161)$ of women were satisfied with their experience (table 4). Maternal overall satisfaction was weakly correlated with total number of peer volunteer contacts $(r=0.35, \mathrm{P}<0.001)$, number of conversations $(r=0.29$, $\mathrm{P}=0.001)$, and number of messages left $(r=0.29$, $\mathrm{P}=0.001)$.

\section{DISCUSSION}

Telephone based peer support might be effective in preventing postnatal depression among women identified as high risk immediately postpartum. In particular, women who received peer support were at half the risk of developing postnatal depression at 12 weeks postpartum than those in the control group. This finding is clinically important as most women who develop postnatal depression do so in the first 12 weeks after childbirth. In terms of feasibility, our results suggest that eight women would need to receive the peer support intervention to prevent one case of postnatal depression. We recruited over 200 peer volunteers, primarily from flyers and newspaper advertisements, and, with the provision of flexible sessions, most of the volunteers were trained and eligible to provide support. On average women received eight contacts from their peer volunteer and each volunteer supported about two mothers. As recruitment of peer volunteers continued throughout the trial, some volunteers did not have an opportunity to support more than one woman. Furthermore, many of the volunteers were still actively participating in the peer support programme when the trial ended, suggesting good retention rates. Importantly, over $80 \%$ of women were satisfied with their peer support experience and would recommend it to a friend.

\section{Strengths and weaknesses}

We used population based screening via a web based system and our participation rate was above $70 \%$. The intervention was pilot tested and standardised through specific selection criteria for peer volunteers, formal training, and structured activities for the volunteer coordinator to ensure initiation of the intervention. Postnatal depression was assessed with the Edinburgh postnatal depression scale, the most commonly used measure in treatment and prevention trials to assess for symptoms of postnatal depression. All self reported outcome measures and procedures were pilot tested, the data collection nurses were trained and assessed for blinding to group allocation, and our losses to followup were below $15 \%$. Women also evaluated their experience of peer support, providing valuable data on acceptance of the intervention. In relation to external validity, we recruited from seven health regions across the province with many participants identifying themselves as of non-Canadian ethnicity; around half of the women were not born in Canada and almost 20\% had moved to Canada about five years previously. Thus, the generalisability of our results is good.

Despite the many strengths, our results are limited in that the clinical diagnostic data for postnatal depression might be questionable. While the structured clinical interview was developed to be administered face to face by a mental health specialist, in our trial it was feasible for the generalist nurses to administer only a shortened

Table $4 \mid$ Maternal perceptions of peer support. Figures are numbers (percentages) of women

\begin{tabular}{lllc} 
Item & $\begin{array}{c}\text { Strongly } \\
\text { agree/ } \\
\text { agree }\end{array}$ & Unsure & $\begin{array}{c}\text { Strongly } \\
\text { disagree/ } \\
\text { disagree }\end{array}$ \\
$\begin{array}{l}\text { My peer provided the } \\
\text { assistance I needed }\end{array}$ & $143(72)$ & $37(19)$ & $18(9)$ \\
\hline My peer met my expectations & $140(70)$ & $39(20)$ & $20(10)$ \\
\hline I liked my peer & $184(92)$ & $13(7)$ & $3(2)$ \\
\hline $\begin{array}{l}\text { Receiving support from my } \\
\text { peer was convenient for me }\end{array}$ & $157(79)$ & $22(11)$ & $19(10)$ \\
\hline $\begin{array}{l}\text { I was able to talk to my peer } \\
\text { when I needed to }\end{array}$ & $144(73)$ & $31(16)$ & $22(11)$ \\
\hline $\begin{array}{l}\text { My peer telephoned when } \\
\text { planned }\end{array}$ & $162(82)$ & $20(10)$ & $17(9)$ \\
\hline $\begin{array}{l}\text { I had enough contact with my } \\
\text { peer }\end{array}$ & $147(74)$ & $24(12)$ & $29(15)$ \\
\hline $\begin{array}{l}\text { I liked the support over the } \\
\text { telephone }\end{array}$ & $157(79)$ & $27(14)$ & $16(8)$ \\
\hline $\begin{array}{l}\text { I would recommend this type } \\
\text { of support to a friend }\end{array}$ & $166(83)$ & $26(13)$ & $8(4)$ \\
\hline $\begin{array}{l}\text { For my situation one to one } \\
\text { support was better than } \\
\text { group support }\end{array}$ & $136(68)$ & $40(20)$ & $24(12)$ \\
\hline $\begin{array}{l}\text { Overall, I am satisfied with my } \\
\text { peer support experience }\end{array}$ & $161(81)$ & $22(11)$ & $17(9)$ \\
\hline & & & \\
\hline
\end{tabular}


version of the depression module by telephone. This had not been formally validated. Furthermore, our sample was significantly more ethnically diverse than the sample in the one previous postnatal depression study that administered the interview by telephone. ${ }^{49}$ While we attempted to be the first postnatal depression prevention trial to administer a diagnostic interview, the depression rates are lower than previous prevalence rate data at 12 weeks postpartum. ${ }^{1}$ Conversely, the results of the Edinburgh postnatal depression scale were consistent with our power analysis, previous research, ${ }^{1}$ and recent work that supports the use of the scale in multiethnic samples. ${ }^{50}$ Additional research would determine how to obtain SCID clinical diag nostic data effectively in large, multisite trials in which face to face interviews are not feasible and the sample is multiethnic. Other limitations include the pragmatic exclusion of women who did not speak English and that for an appreciable proportion of women in the intervention group peer volunteers did not return activity logs. This might indicate that some women had limited interaction with their peer volunteer, despite our request for a minimum of four contacts. Furthermore, there is evidence that the intervention was not initiated in a few cases. These findings highlight the critical role of the peer volunteer coordinator in initiation of the intervention and compliance of volunteers.

\section{Comparison with other research}

Our results are consistent with those in a large Cochrane review, which suggests that interventions to prevent postnatal depression are more likely to be successful if they are individually based, initiated postnatally, and target high risk women. ${ }^{13}$ Our study is also one of the few trials that showed a preventative effect for postnatal depression, ${ }^{2829}$ evaluated a secondary preventive intervention where women were screened for depressive symptoms in the first two weeks postpartum, and examined the effect of any peer/lay intervention in the prevention of postnatal depression. As such, this trial is original and makes an important contribution to research on postnatal depression. Furthermore, our findings could be applied in community based settings to devise policies regarding strategies to prevent postnatal depression.

Our results are also consistent with research linking depressive symptoms with smaller social networks, fewer close relationships, and lower perceived adequacy of social support. ${ }^{5152}$ Furthermore, our findings provide evidence that lay people who have experienced a similar health problem or stressor can have a positive effect on psychological wellbeing. ${ }^{534}$ There are several possible explanations as to why the peer volunteers prevented depressive symptoms in the first 12 weeks postpartum. Members of a social network can exert a salutary influence on mental health by role modelling health relevant behaviours. ${ }^{55}$ Integration in a social network might also directly produce positive psychological states, including a sense of purpose, belonging, and recognition of self worth. ${ }^{54}$ These positive states, in turn, might benefit mental health because of an increased motivation for self care, as well as the modulation of the neuroendocrine response to stress. ${ }^{54}$ Being part of a broader social structure (such as involvement in social networks and immersion in close relationships) enhances the likelihood of accessing various forms of support, which in turn protects against distress. ${ }^{56}$ Finally, the perceived availability of social support in the face of a stressful event might have led to a more benign appraisal of the situation, thereby preventing a cascade of ensuing negative emotional and behavioural responses. ${ }^{57}$ While the causal pathway is unknown, theoretically all are viable options.

Anxiety often occurs with depression, ${ }^{58}$ and in our trial there was a trend for women in the intervention group to have lower levels of anxiety at 12 weeks postpartum. Fourteen independent prospective studies have shown a relation between antenatal maternal anxiety or stress and cognitive, behavioural, and emotional problems in the child. ${ }^{59}$ The continuity of antenatal anxiety into the postpartum period is also well documented, ${ }^{58}$ with postnatal anxiety being linked to poor maternal-infant interactions. ${ }^{60}$ Despite these findings, maternal anxiety has received little empirical attention, ${ }^{61}$ and further research examining the prevention and treatment of this condition is warranted.

Consistent with previous research, a history of depression was a significant risk factor for the development of postnatal depression. ${ }^{11}$ One unique finding, however, was the importance of self reported nonCanadian ethnicity and living in Canada for less than five years in the presentation of depressive symptoms in the immediate postpartum period. Among the few studies that have examined immigrant status, all have found this variable to be significantly related to postnatal depression. ${ }^{36263}$ While scant research has been conducted as to why these women are at risk, investigations with general immigrant populations have clearly shown a link between the acculturation process and psychological problems. ${ }^{6465}$ Acculturation refers to the process of adjusting to life modifications, and, depending on the disparity between the two cultures, acculturative stress is a common outcome often resulting in an increased risk of depression. ${ }^{6466}$ While considerable attention has been paid to the importance of acculturative stress on depression among populations of immigrants ${ }^{2566-71}$ and the impact of stressful life events on maternal mood, ${ }^{11}$ the relation between acculturation, acculturative stress, and postnatal depression has received scant attention.

The number of contacts with peer volunteers was significantly correlated with depression scores at 12 weeks, suggesting that mothers with depressive symptoms were receptive to the peer support intervention. This finding also indicates that the peer volunteers could identify potentially depressed mothers and respond to individual needs for support. Given that the aetiology of postnatal depression is multifactorial, ${ }^{11}$ it is not surprising that peer support was not protective for all women and that referrals to health professionals were required. Consistent with previous research, ${ }^{72}$ women positively evaluated their 


\section{WHAT IS ALREADY KNOWN ON THIS TOPIC}

About $13 \%$ of women from diverse cultures will experience postnatal depression

Social deficiencies significantly increase the risk of postnatal depression

Preventative interventions are more likely to be successful if they are individually based, initiated postnatally, and target high risk women

\section{WHAT THIS STUDY ADDS}

Telephone based peer support might be effective in preventing postnatal depression among women at high risk

Women are receptive to receiving telephone based peer support and are satisfied with their experience

Lay people who have experienced a similar health problem or stressor can have a positive effect on psychological wellbeing
4 Hipwell AE, Goossens FA, Melhuish EC, Kumar R. Severe maternal psychopathology and infant-mother attachment. Dev Psychopathol 2000;12:157-75.

5 Murray L. The impact of postnatal depression on infant development.) Child Psychol Psychiatry 1992;33:543-61.

6 Cogill SR, Caplan HL, Alexandra H, Robson KM, Kumar R. Impact of maternal postnatal depression on cognitive development of young children. BMJ 1986;292:1165-7.

7 Cummings EM, Davies PT. Maternal depression and child development. J Child Psychol Psychiatry 1994;35:73-112.

8 Murray L, Sinclair D, Cooper P, Ducournau P, Turner P, Stein A. The socioemotional development of 5-year-old children of postnatally depressed mothers. / Child Psychol Psychiatry 1999;40:1259-71.

9 Buist A. Childhood abuse, parenting and postpartum depression. Aust N Z J Psychiatry 1998;32:479-87.

10 Cooper P, Murray L. Prediction, detection, and treatment of postnatal depression. Arch Dis Child 1997;77:97-9.

11 Beck CT. Predictors of postpartum depression: an update. Nurs Res 2001;50:275-85.

12 Dennis CL, Hodnett E. Psychosocial and psychological interventions for treating postpartum depression. Cochrane Database Syst Rev 2007;(4):CD006116.

13 Dennis CL. Psychosocial and psychological interventions for prevention of postnatal depression: systematic review. BMJ 2005;331:15.

experience of telephone based peer support. Traditionally, support has been provided through groups, but these tend to be poorly attended by new mothers and those who are feeling depressed. Telephone based support interventions are not only flexible, private, and non-stigmatising but they also reduce differences related to socioeconomic status and traditional healthcare barriers such as accessibility because of transportation difficulties or geography. ${ }^{7374}$ While in the past decade advances in technology, such as the use of email and the internet, have enhanced the range of options available for "home to home" support, the telephone remains the most accessible for most people. ${ }^{75}$

Contributions: C-LD (principal investigator) conceptualised and designed the trial, obtained funding, directed implementation, completed data analysis and interpretation, wrote the draft manuscript, and is guarantor. EH (coinvestigator) assisted in all trial activities including design, funding, implementation, data interpretation, and manuscript preparation. LK (trial coordinator) assisted in all trial implementation procedures including managing the population based screening activities, completing participant recruitment, overseeing intervention implementation and data collection procedures, and performing database management activities. JW (senior trial coordinator) assisted in all trial activities including design, funding, budget management, implementation, database management, data interpretation, and manuscript preparation. JZ (coinvestigator and health economist) assisted in designing the trial economic evaluation, obtaining funding, and data interpretation. DS (coinvestigator and psychiatrist) assisted in trial funding and was available for clinical consultation during implementation. AK (coinvestigator and biostatistician) assisted in trial funding, data analysis, data interpretation, and manuscript preparation. All authors have commented on the manuscript.

Funding: This work was supported by the Canadian Institutes of Health Research grant number MCT 66874. This trial was conducted and data analysed with complete independence of the researchers from the Canadian Institutes of Health Research.

Competing interests: None declared.

Ethical approval: This study was approved by the University of Toronto ethics committee and ethical review boards of participating health regions. Informed consent was given by all participants.

Provenance and peer review: Not commissioned; externally peer reviewed.

1 O'Hara M, Swain A. Rates and risk of postpartum depression-a metaanalysis. Int Rev Psychiatry 1996;8:37-54.

2 Murray L, Fiori-Cowley A, Hooper R, Cooper P. The impact of postnata depression and associated adversity on early mother-infant interactions and later infant outcome. Child Dev 1996;67:2512-26.

3 Mayberry LJ, Affonso DD. Infant temperament and postpartum depression: a review. Health Care Women Int 1993;14:201-11.
14 Brugha TS, Sharp HM, Cooper SA, Weisender C, Britto D, Shinkwin R, et al. The Leicester 500 Project. Social support and the development Psychol Med 1998;28:63-79.

15 Paykel ES, Emms EM, Fletcher J, Rassaby ES. Life events and social support in puerperal depression. Br J Psychiatry 1980;136:339-46.

16 Romito P, Saurel-Cubizolles MJ, Lelong N. What makes new mothers unhappy: psychological distress one year after birth in Italy and France. Soc Sci Med 1999;49:1651-61.

17 O'Hara MW, Rehm LP, Campbell SB. Postpartum depression. A role fo social network and life stress variables. J Nerv Ment Dis 1983;171:336-41.

18 Mills EP, Finchilescu G, Lea SJ. Postnatal depression-an examination of psychosocial factors. S Afr Med J 1995;85:99-105.

19 Small R, Johnston V, Orr A. Depression after childbirth: the views of medical students and women compared. Birth 1997;24:109-15.

20 Cox JL, Holden JM, Sagovsky R. Detection of postnatal depression. Development of the 10-item Edinburgh postnatal depression scale. BrJ Psychiatry 1987;150:782-6.

21 Dennis CL, Letourneau N. Global and relationship-specific perceptions of support and the development of postpartum depressive symptomatology. Soc Psychiatry Psychiatr Epidemiol 2007;42:389-95.

22 Dennis CL, Stewart DE. Treatment of postpartum depression, part 1: a critical review of biological interventions. J Clin Psychiatry 2004;65:1242-51.

23 Dennis CL. Treatment of postpartum depression, part 2: a critical review of nonbiological interventions. J Clin Psychiatry 2004;65:1252-65

24 Dennis CL. Can we identify mothers at risk for postpartum depression in the immediate postpartum period using the Edinburgh postnatal depression scale? J Affect Dis 2004;78:163-9.

25 Dennis CL. The effect of peer support on postpartum depression: a pilot randomized controlled trial. Can J Psychiatry 2003;48:115-24.

26 Dennis CL, Hodnett E, Gallop R, Chalmers B. The effect of peer support on breast-feeding duration among primiparous women: a randomized controlled trial. CMAJ 2002;166:21-8.

27 Spitzer RL, Williams JB, Gibbon M, First MB. The structured clinical interview for DSM-III-R (SCID). I: history, rationale, and description. Arch Gen Psychiatry 1992;49:624-9.

28 Dennis CL. Preventing postpartum depression part I: a review of biological interventions. Can J Psychiatry 2004;49:467-75.

29 Dennis CL. Preventing postpartum depression part II: a critical review of nonbiological interventions. Can J Psychiatry 2004;49:526-38.

30 Affonso DD, De AK, Horowitz JA, Mayberry LJ. An international study exploring levels of postpartum depressive symptomatology. J Psychosom Res 2000;49:207-16.

31 Segal DL, Hersen M, Van Hasselt VB. Reliability of the structured clinical interview for DSM-III-R: an evaluative review. Compr Psychiatry 1994;35:316-27.

32 Spielberger CD. STAI manual for the state-trait anxiety inventory Palo Alto, CA: Consulting Psychologists Press, 1970.

33 Russell DW.UCLA Loneliness Scale (version 3): reliability, validity, and factor structure. J Pers Assess 1996;66:20-40.

34 Brown G. Health service utilization and cost of care questionnaire. Hamilton, ON: Health and Social Service Utilization Research Unit, McMaster University, 2001.

35 Dennis CL. Influence of depressive symptomatology on maternal health service utilization and general health. Arch Women Ment Health 2004;7:183-91 of postnatal depressive symptoms, a prospective cohort survey. 
36 Dennis CL, Janssen PA, Singer J. Identifying women at-risk for postpartum depression in the immediate postpartum period. Acta Psychiatr Scand 2004;110:338-46.

37 Chabrol H, Teissedre F, Saint-Jean M, Teisseyre N, Sistac C, Michaud C, et al. Detection, prevention and treatment of postpartum depression: a randomized, controlled study on a sample of 859 women. Encephale 2002;28:65-70.

38 Holden JM, Sagovsky R, Cox JL. Counselling in a general practice setting: controlled study of health visitor intervention in treatment of postnatal depression. BMJ 1989;298:223-6.

39 Wickberg B, Hwang CP. Counselling of postnatal depression: a controlled study on a population based Swedish sample. J Affect Dis 1996;39:209-16.

40 Chen CH, Wang SY, Hwu HG, Chou FH. A controlled study of postpartum depression in adult women. Kaohsiung J Med Sci 2000;16:156-61.

41 Harrell F. Regression modeling strategies New York: Springer Verlag, 2001.

42 Beck CT, Reynolds MA, Rutowski P. Maternity blues and postpartum depression. / Obstet Gynecol Neonatal Nurs 1992;21:287-93.

43 Fossey L, Papiernik E, Bydlowski M. Postpartum blues: a clinical syndrome and predictor of postnatal depression? J Psychosom Obstet Gynecol 1997;18:17-21.

44 Hapgood CC, Elkind GS, Wright JJ. Maternity blues: phenomena and relationship to later post partum depression. Aust N Z J Psychiatry 1988;22:299-306.

45 Lane A, Keville R, Morris M, Kinsella A, Turner M, Barry S. Postnatal depression and elation among mothers and their partners: prevalence and predictors. Br J Psychiatry 1997;171:550-5

46 Yoshida K, Marks MN, Kibe N, Kumar R, Nakano H, Tashiro N. Postnatal depression in Japanese women who have given birth in England. J Affect Dis 1997;43:69-77.

47 Hannah P, Adams D, Lee A, Glover V, Sandler M. Links between early post-partum mood and post-natal depression. Br J Psychiatry 1992;160:777-80.

48 Yamashita H, Yoshida K, Nakano H, Tashiro N. Postnatal depression in Japanese women. Detecting the early onset of postnatal depression by closely monitoring the postpartum mood. J Affect Dis 2000;58:145-54.

49 O'Hara MW, Stuart S, Gorman LL, Wenzel A. Efficacy of interpersonal psychotherapy for postpartum depression. Arch Gen Psychiatry 2000;57:1039-45.

50 Small R, Lumley J, Yelland J, Brown S. The performance of the Edinburgh postnatal depression scale in English speaking and nonEnglish speaking populations in Australia. Soc Psychiatr Psychiatric Epidemiol 2007;42:70-8.

51 Kawachi I, Berkman LF. Social ties and mental health. J Urban Health 2001;78:458-67.

52 Barnett PA, Gotlib IH. Psychosocial functioning and depression: distinguishing among antecedents, concomitants, and consequences. Psychol Bull 1988;104:97-126.

53 Dennis CL. Peer support within a health care context: a concept analysis. Int J Nurs Stud 2003;40:321-32

54 Cohen S, Underwood L, Gottlieb B, eds. Social support measurement and intervention: a guide for health and social scientists. New York: Oxford University Press, 2002.

55 Berkman L, Glass T. Social integration, social networks, social support, and health. In: Berkman L, Kawachi I, eds. Social epidemiology. New York: Oxford University Press, 2000:137-73.
56 Lin N, Ye X, Ensel WM. Social support and depressed mood: a structural analysis. J Health Soc Behav 1999;40:344-59.

57 Thoits PA. Social support as coping assistance. / Consult Clin Psychol 1986;54:416-23.

58 Heron J, O'Connor TG, Evans J, Golding J, Glover V, ALSPAC Study Team. The course of anxiety and depression through pregnancy and the postpartum in a community sample. J Affect Dis 2004;80:65-73.

59 Van den Bergh BR, Mulder EJ, Mennes M, GloverV. Antenatal maternal anxiety and stress and the neurobehavioural development of the fetus and child: links and possible mechanisms. A review. Neuroscience Biobehav Rev 2005;29:237-58.

60 Nicol-Harper R, Harvey AG, Stein A. Interactions between mothers and infants: impact of maternal anxiety. Infant Behav Develop 2007;30:161-7.

61 Ross LE, McLean LM. Anxiety disorders during pregnancy and the postpartum period: a systematic review. J Clin Psychiatry 2006;67:1285-98.

62 Zelkowitz P, Milet TH. Screening for post-partum depression in a community sample. Can J Psychiatry 1995;40:80-6.

63 Stewart DE, Gagnon A, Saucier J, Wahoush O, Dougherty G. Postpartum depression symptoms in newcomers. Can J Psychiatry 2008;53:121-4.

64 Williams CL, Berry JW. Primary prevention of acculturative stress among refugees. Application of psychological theory and practice. Am Psychology 1991;46:632-41.

65 Bhugra D. Migration and mental health. Acta Psychiatr Scand 2004;109:243-58.

66 Constantine MG, Okazaki S, Utsey SO. Self-concealment, social selfefficacy, acculturative stress, and depression in African, Asian, and Latin American international college students. Am J Orthopsychiatry 2004;74:230-41.

67 Aroian KJ, Norris A. Assessing risk for depression among immigrants at two-year follow-up. Arch Psychiatr Nurs 2002;16:245-53.

68 Vega WA, Kolody B, Valle JR. Migration and mental health: an empirical test of depression risk factors among immigrant Mexican women. Int Migr Rev 1987;21:512-30.

69 Oh Y, Koeske GF, Sales E. Acculturation, stress, and depressive symptoms among Korean immigrants in the United States. / Soc Psychol 2002;142:511-26.

70 Miller AM, Chandler PJ. Acculturation, resilience, and depression in midlife women from the former Soviet Union. Nurs Res 2002;51:26-32.

71 Hovey JD. Psychosocial predictors of depression among Central American immigrants. Psychol Rep 2000;86:1237-40.

72 Dennis CL. Breastfeeding peer support: maternal and voluntee perceptions from a randomized controlled trial. Birth 2002;29:169-76.

73 Thome M, Alder B. A telephone intervention to reduce fatigue and symptom distress in mothers with difficult infants in the community. I Adv Nurs 1999;29:128-37.

74 Galinsky MJ, Schopler JH, Abell MD. Connecting group members through telephone and computer groups. Health Soc Work 1997;22:181-8

75 Horton R, Peterson MG, Powell S, Engelhard E, Paget SA. Users evaluate LupusLine, a telephone peer counseling service. Arthritis Care Res 1997;10:257-63.

Accepted: 27 October 2008 